\title{
MathematicaL
}

MoDELING OF

Pharmacokinetic

DATA

David W. A. Bourne, Ph.D. 


\section{Mathematical Modeling of Pharmacokinetic Data}


$\because$ Taylor \& Francis

Taylor \& Francis Group

http://taylorandfrancis.com 


\section{MATHEMATICAL}

MoDELING

OF

Pharmacokinetic

DATA

\section{David W. A. Bourne, Ph.D.}

College of Pharmacy

Health Sciences Center

Oklahoma University

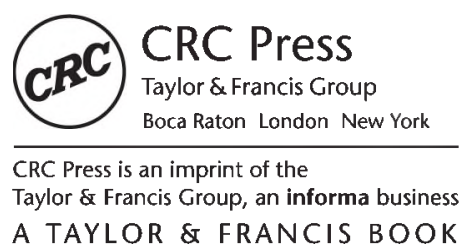




\title{
Library of Congress Cataloging-in-Publication Data
}

Main entry under title:

Mathematical Modeling of Pharmacokinetic Data

This book contains information obtained from authentic and highly regarded sources. Reprinted material is quoted with permission, and sources are indicated. A wide variety of references are listed. Reasonable efforts have been made to publish reliable data and information, but the author and the publisher cannot assume responsibility for the validity of all materials or for the consequences of their use.

Neither this book nor any part may be reproduced or transmitted in any form or by any means, electronic or mechanical, including photocopying, microfilming, and recording, or by any information storage or retrieval system, without prior permission in writing from the publisher.

The consent of CRC Press does not extend to copying for general distribution, for promotion, for creating new works, or for resale. Specific permission must be obtained in writing from CRC Press for such copying.

Direct all inquiries to CRC Press, 2000 N.W. Corporate Blvd., Boca Raton, Florida 33431.

Trademark Notice: Product or corporate names may be trademarks or registered trademarks, and are used only for identification and explanation, without intent to infringe.

\section{Visit the CRC Press Web site at www.crcpress.com}

\author{
(C) 1995 by CRC Press
}

No claim to original U.S. Government works

International Standard Book Number 1-56676-204-9

Library of Congress Catalog Number 04-61269 
For Geoffrey, Katrina, and Aaron 
$\because$ Taylor \& Francis

Taylor \& Francis Group

http://taylorandfrancis.com 
Preface ix

Chapter 1. Why Model the Data? . . . . . . . . . . . 1

1.1 Condense the Data 1

1.2 Exploring Mechanisms 4

1.3 Making Predictions 7

Chapter 2. General Approach $\ldots \ldots \ldots \ldots \ldots \ldots \ldots \ldots$

2.1 General Method 9

2.2 Error in $y$ Alone 15

2.3 Parameter Adjustments 17

Chapter 3. Pharmacokinetic Models

3.1 Compartmental Models 19

3.2 Physiologically Based Models 30

3.3 Pharmacodynamic Models 33

Chapter 4. Simulation of Data

4.1 Explicit Equations 35

4.2 Implicit Equations 38

4.3 Differential Equations 40

4.4 Integration Using Laplace Transforms 41

4.5 Numerical Integration of Differential Equations 49

Chapter 5. Initial Estimates

5.1 Graphical Methods 57

5.2 Linear Regression 61 
viii Contents

5.3 Curve Stripping 62

5.4 Area under the Curve Estimation 64

5.5 Deconvolution 67

Chapter 6. Nonlinear Regression . . . . . . . . . . . . . . . . 75

6.1 Grid Search Method 75

6.2 Steepest Descent Method 77

6.3 Gauss-Newton Methods 78

6.4 Simplex Method 80

6.5 Local Minima 82

Chapter 7. Weighting Schemes

7.1 Equal Weight 83

7.2 Variance Model 85

7.3 Iteratively Reweighted Least Squares $\quad \mathbf{8 7}$

7.4 Extended Least Squares 87

7.5 Bayesian Methods 88

7.6 Analysis of Population Data 90

Chapter 8. Evaluation of Program Output

8.1 Tabular Output 95

8.2 Graphical Output 100

8.3 Statistical Output 106

Chapter 9. Experimental Design

9.1 Pilot Study 111

9.2 Identifiability - Sampling Sites 114

9.3 Optimal Sampling-Sampling Times 123

9.4 Model Testing 129

Appendix 131

References 133

Index 137 
In the field of pharmacokinetics, data analysis seems to be going in different directions. There are many investigators looking at small numbers of data points per subject over many subjects, as in "population analysis." Then there are other investigators taking a minimal approach to modeling using a "noncompartmental approach." The first group is using highly sophisticated techniques to extract pharmacokinetic information about various study populations. In the process some model structure may be ignored. For example, the absorption process present after oral absorption may be left out of the model used in a population analysis because there may be little suitable data to characterize the process. The second group is using mathematically simple techniques to get an overview of drug disposition. This is sometimes done because of the paucity of data or available tools. It has been suggested, inappropriately, that there may not be enough data to perform mathematically modeling analyses so a simple AUC was calculated. In reality, if the data cannot support a modeling approach, the AUC values are not likely to be very accurate.

There is much middle ground that this book hopes to address. There are many well designed studies that can be analyzed using a structured modeling approach. The mathematical tools are available for mainframe and desktop computers. These programs are relatively inexpensive. The hardware to run these programs is also becoming increasingly affordable. The objective of this book is to present a systematic approach to using these tools so that the investigator may extract the maximum information from a given set of data.

This book presents topics that may be included in a one-semester course to advanced undergraduates, graduate students, or professional pharmacy students. Scholars in other fields may also find this material of interest. The 
scientist designing or analyzing drug disposition studies may find this book useful. Scientists in other areas may have data that should be modeled. Hopefully, many of the techniques described in this book will be effective.

The book begins with a rationale for mathematical modeling followed by a brief description of the general approach that may be taken. Mathematical models from any field may be analyzed by some of the techniques described in this book, however, a brief review of pharmacokinetic models is presented to provide a common framework for the following chapters. Mathematical models are ultimately expressed as equations. These equations may take different forms, each of which must be calculated appropriately. A major objective is to determine the best estimates of various parameter values. There are a number of techniques for determining initial estimates of these parameters, including graphical methods, linear regression, curve stripping, and area under the curve estimation or deconvolution. Many models found in pharmacokinetics are nonlinear, and thus, nonlinear regression techniques are required for their analysis. Data weighting should be considered. Other topics of a similar nature include extended least squares, Bayesian analysis, and the analysis of population data. Once the results are computed it is necessary to evaluate the tabular, graphical, and statistical output provided by the program. Correct data, correct model specification, appropriate model, and appropriate weighting scheme can all be evaluated by consideration of the program output. The final chapter describes questions of experimental design and covers topics such as pilot study considerations, identifiability of parameter values, and optimal sampling time selection.

These topics have been presented in workshops and seminars as well as to various graduate and professional students. The author would like to thank these participants for their suggestions and feedback. The assistance provided by Steven Strauss and others at Technomic Publishing Company is gratefully acknowledged.

DAVID BOURNE Oklahoma City, OK 


\section{Why Model the Data?}

Modeling of data set or sets is not a trivial undertaking. There are many questions that must be answered. What do you want to achieve from the modeling? What type of models do you wish to consider? How good are the data; for each data point, which weighting schemes should be considered? Which is the best model and the best weighting scheme? Have sufficient experiments been performed and if not, what further experiments should be conducted? Finding answers to these questions may take a considerable amount of thought, time, and computer resources. Consequently, one should have good reasons for undertaking the modeling process. Why model the data? Why do we want to use a mathematical model?

A successful model will allow considerable consolidation of the collected data. Experimental results covering pages of tabular data may be represented with a model description and a few parameter values. By going through the process of considering a group of models and selecting a best model, exploration of basic mechanisms becomes possible and may be necessary. Future experiments can be designed more precisely using an appropriate model. Finally, successful determination of a good model and model parameters allows the prediction of future results. Dose calculations rely on the existence of a suitable model.

\subsection{CONDENSE THE DATA}

Where do we start? Do we collect data to develop the model, or do we use a model to get the best from the data? The analyst may be confronted with a large amount of data that needs to be understood. One logical approach is to analyze the data using appropriate mathematical models, each with a few 
TABLE 1.1. Plasma Concentrations Measured after IV Bolus Administration.

\begin{tabular}{|c|c|c|c|c|c|}
\hline \multicolumn{2}{|c|}{$\begin{array}{c}\text { Subject \#1 } \\
\text { Wt: } 76 \mathrm{~kg} \\
\text { Dose } 200 \mathrm{mg}\end{array}$} & \multicolumn{2}{|c|}{$\begin{array}{c}\text { Subject \#2 } \\
\text { Wt: } 74 \mathrm{~kg} \\
\text { Dose } 200 \mathrm{mg}\end{array}$} & \multicolumn{2}{|c|}{$\begin{array}{c}\text { Subject \#3 } \\
\text { Wt: } 54 \mathrm{~kg} \\
\text { Dose } 150 \mathrm{mg}\end{array}$} \\
\hline $\begin{array}{l}\text { Time } \\
\text { (hr) }\end{array}$ & $\begin{array}{c}\text { Concentration } \\
(\mathrm{mg} / \mathrm{L})\end{array}$ & $\begin{array}{c}\text { Time } \\
\text { (hr) }\end{array}$ & $\begin{array}{c}\text { Concentration } \\
(\mathrm{mg} / \mathrm{L})\end{array}$ & $\begin{array}{c}\text { Time } \\
\text { (hr) }\end{array}$ & $\begin{array}{c}\text { Concentration } \\
(\mathrm{mg} / \mathrm{L})\end{array}$ \\
\hline 1.0 & 18.6 & 1.0 & 19.3 & 1.0 & 19.3 \\
\hline 2.0 & 15.6 & 2.0 & 15.8 & 2.0 & 14.5 \\
\hline 4.0 & 12.3 & 4.0 & 11.5 & 4.0 & 12.5 \\
\hline 8.0 & 10.1 & 8.0 & 9.8 & 8.0 & 10.3 \\
\hline 12.0 & 7.6 & 12.0 & 6.5 & 12.0 & 6.9 \\
\hline 24.0 & 3.2 & 24.0 & 2.1 & 24.0 & 3.5 \\
\hline \multicolumn{2}{|c|}{$\begin{array}{c}\text { Subject \#4 } \\
\text { Wt: } 58 \mathrm{~kg} \\
\text { Dose } 150 \mathrm{mg}\end{array}$} & \multicolumn{2}{|c|}{$\begin{array}{c}\text { Subject \#5 } \\
\text { Wt: } 94 \mathrm{~kg} \\
\text { Dose } 250 \mathrm{mg}\end{array}$} & \multicolumn{2}{|c|}{$\begin{array}{c}\text { Subject \#6 } \\
\text { Wt: } 82 \mathrm{~kg} \\
\text { Dose } 225 \mathrm{mg}\end{array}$} \\
\hline $\begin{array}{c}\text { Time } \\
\text { (hr) }\end{array}$ & $\begin{array}{l}\text { Concentration } \\
(\mathrm{mg} / \mathrm{L})\end{array}$ & $\begin{array}{l}\text { Time } \\
\text { (hr) }\end{array}$ & $\begin{array}{l}\text { Concentration } \\
(\mathrm{mg} / \mathrm{L})\end{array}$ & $\begin{array}{l}\text { Time } \\
\text { (hr) }\end{array}$ & $\begin{array}{c}\text { Concentration } \\
(\mathrm{mg} / \mathrm{L})\end{array}$ \\
\hline 1.0 & 18.9 & 1.0 & 19.5 & 1.0 & 18.7 \\
\hline 2.0 & 14.6 & 2.0 & 14.7 & 2.0 & 14.9 \\
\hline 4.0 & 12.7 & 4.0 & 12.3 & 4.0 & 12.3 \\
\hline 8.0 & 10.3 & 8.0 & 10.7 & 8.0 & 10.3 \\
\hline 12.0 & 7.5 & 12.0 & 6.9 & 12.0 & 7.9 \\
\hline 24.0 & 3.3 & 24.0 & 4.1 & 24.0 & 3.5 \\
\hline
\end{tabular}

parameters. Thus many pages of data may be summarized as a model with a small number of parameter values. For example, the data in Table 1.1 may have been collected after a pharmacokinetic study in six subjects. These data were collected after an IV bolus dose to each subject. After plotting the data on semi-log graph paper (Figure 1.1), a one-compartment pharmacokinetic model was selected. This model can be defined in terms of a differential equation [Equation (1.1)] or an integrated equation [Equation (1.2)].

$$
\begin{gathered}
\frac{d C}{d t}=-k_{e l} \cdot C \quad C_{0}=\frac{\text { dose }}{V} \\
C=\frac{\text { dose }}{V} \cdot e^{-k_{e l} \cdot t}
\end{gathered}
$$




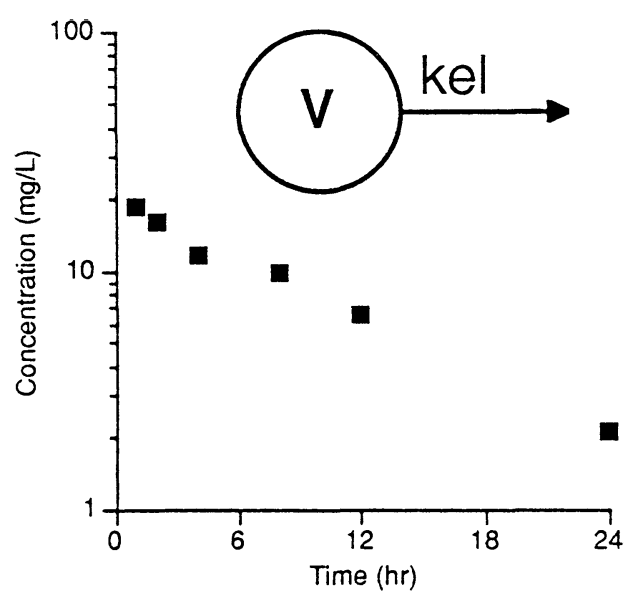

FIGURE 1.1. Data from Subject 1 plotted as a semi-log graph with a diagrammatic representation of a one-compartment pharmacokinetic model.

Nonlinear regression analysis of these data (Bourne, 1989), using a weighting scheme proportional to the reciprocal of the observed data, resulted in the parameter values shown in Table 1.2. Thus, all of the data in Table 1.1 can be represented or summarized as

$$
\begin{aligned}
k_{e l} & =0.0757 \pm 0.0088 \mathrm{hr}^{-1} \\
V & =10.7 \pm 2.3 \mathrm{~L}=0.147 \pm 0.006 \mathrm{~L} / \mathrm{kg}
\end{aligned}
$$

The data from all six subjects can be condensed since they are consistent

TABLE 1.2. Parameter Values Obtained atter Non-Linear Regression Analysis of the Data in Table 1.1.

\begin{tabular}{|ccccccc|}
\hline Subject & Dose $(\mathrm{mg})$ & Wt $(\mathrm{kg})$ & $A(\mathrm{mg} / \mathrm{L})$ & $k_{e l}\left(\mathrm{hr}^{-1}\right)$ & $V(\mathrm{~L})$ & $V(\mathrm{~L} / \mathrm{kg})$ \\
\hline 1 & 200 & 76 & 18.37 & 0.07485 & 10.887 & 0.1433 \\
2 & 200 & 74 & 19.31 & 0.09297 & 10.357 & 0.1400 \\
3 & 150 & 54 & 18.11 & 0.07407 & 8.283 & 0.1534 \\
4 & 150 & 58 & 18.15 & 0.07298 & 8.264 & 0.1425 \\
5 & 250 & 94 & 17.92 & 0.06937 & 13.951 & 0.1484 \\
6 & 225 & 82 & 17.91 & 0.06970 & 12.563 & 0.1532 \\
Mean & & & & 0.0757 & 10.7 & 0.147 \\
Std Dev & & & & 0.0088 & 2.3 & 0.006 \\
CV (\%) & & & & 11.6 & 21.3 & 3.91 \\
\hline
\end{tabular}


with a one-compartment pharmacokinetic model with two parameters, $k_{e l}$ and $V$. Even from these data it can be observed that the variation in $V$ is somewhat smaller when expressed on a per $\mathrm{kg}$ basis [coefficient of variation (CV) $21.3 \%$ versus $3.91 \%$ ]. Modeling the data can, not only summarize the results, but also can lead the alert investigator to develop a more detailed understanding of the experiment and the results.

\subsection{EXPLORING MECHANISMS}

Mathematical modeling of experimental data can be an excellent method of exploring the mechanisms involved in the process under investigation. Analysis of the experimental data can lead to an empirical representation. From this empirical representation it may be possible to develop a theoretical basis for the observations. An example of such an approach is the analysis of the data in Table 1.3. Concentration versus time data from a number of patients was modeled using a one-compartment pharmacokinetic model. The results of this analysis are presented in Table 1.3 along with various patient demographics, including estimates of the patient's creatinine clearance. The linear plot of $k_{e l}$ versus $C L_{C R}$, creatinine clearance (Figure 1.2), indicates that there is a strong linear relationship between these two variables. Thus, a straight line equation [or model, Equation (1.3)] could be used to analyze these data. Thus,

$$
k_{e l}=a+b \cdot C L_{C R}
$$

or

$$
k_{e l}=0.0355+0.00386 \times C L_{C R}
$$

This analysis indicates that the drug elimination is dependent on kidney

TABLE 1.3. Parameter Values Obtained in Patients with Various Values of Creatinine Clearance, $\mathrm{CL}_{\mathrm{CA}}$.

\begin{tabular}{|cccccccc|}
\hline Subject & Wt $(\mathrm{kg})$ & Sex & $\begin{array}{c}C L_{C R} \\
(\mathrm{ml} / \mathrm{min})\end{array}$ & Dose $(\mathrm{mg})$ & $\left.k_{\theta /}(\mathrm{hr})^{-1}\right)$ & $V(\mathrm{~L})$ & $V(\mathrm{~L} / \mathrm{kg})$ \\
\hline 1 & 75 & F & 102 & 200 & 0.38 & 15.2 & 0.203 \\
2 & 68 & F & 34 & 175 & 0.13 & 13.2 & 0.194 \\
3 & 65 & F & 21 & 175 & 0.10 & 13.1 & 0.202 \\
4 & 98 & M & 54 & 250 & 0.28 & 19.4 & 0.198 \\
5 & 56 & M & 65 & 150 & 0.32 & 11.2 & 0.200 \\
6 & 76 & M & 76 & 200 & 0.36 & 15.5 & 0.204 \\
- & - & - & - & - & - & - & - \\
\hline
\end{tabular}




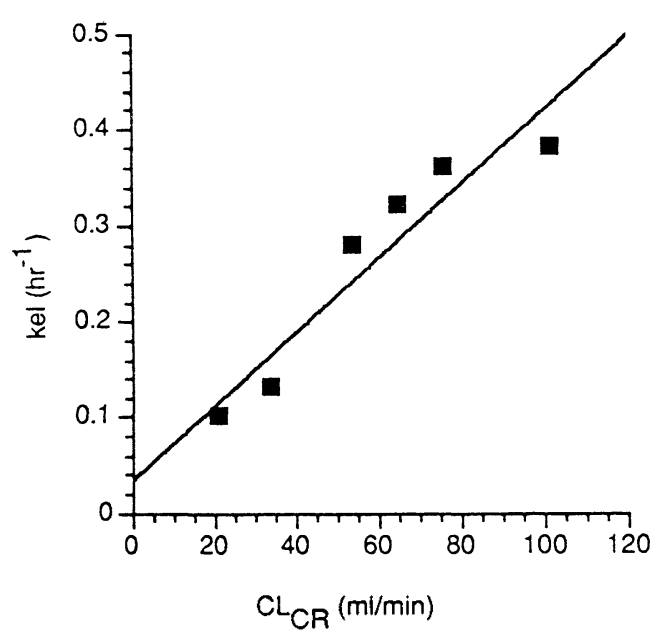

FIGURE 1.2. Plot of elimination rate constant versus creatinine clearance.

function, expressed as the estimate of creatinine clearance. A more complete analysis of the data or a larger sample size might suggest a more complex analysis. Thus modeling the data should give a useful insight into the mechanisms involved. Analysis of the parameter apparent volume of distribution $V$ results in a different picture (Figure 1.3). From this plot it appears that the value of $V$ is independent of creatinine clearance.

The data in Table 1.4 provides another modeling exercise. These data

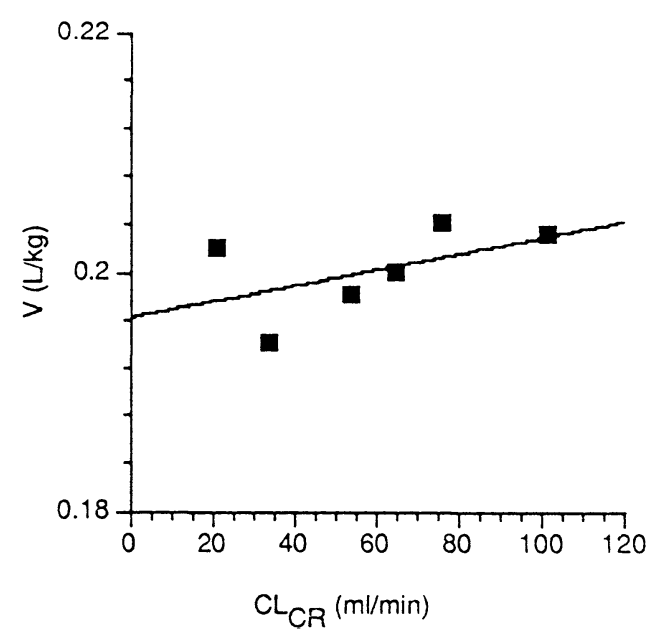

FIGURE 1.3. Plot of apparent volume of distribution versus creatinine clearance. 
TABLE 1.4. Drug Concentrations Measured after IV Bolus Administration.

\begin{tabular}{|c|c|c|c|c|c|}
\hline \multicolumn{2}{|c|}{ Dose $25 \mathrm{mg}$} & \multicolumn{2}{|c|}{ Dose $100 \mathrm{mg}$} & \multicolumn{2}{|c|}{ Dose $500 \mathrm{mg}$} \\
\hline $\begin{array}{l}\text { Time } \\
\text { (hr) }\end{array}$ & $\begin{array}{c}\text { Concentration } \\
(\mathrm{mg} / \mathrm{L})\end{array}$ & $\begin{array}{c}\text { Time } \\
\text { (hr) }\end{array}$ & $\begin{array}{l}\text { Concentration } \\
(\mathrm{mg} / \mathrm{L})\end{array}$ & $\begin{array}{c}\text { Time } \\
\text { (hr) }\end{array}$ & $\begin{array}{l}\text { Concentration } \\
(\mathrm{mg} / \mathrm{L})\end{array}$ \\
\hline 0.0 & 2.03 & 0.0 & 8.13 & 0.0 & 40.6 \\
\hline 0.5 & 1.83 & 0.5 & 7.62 & 0.5 & 39.8 \\
\hline 1.0 & 1.65 & 1.0 & 7.14 & 1.0 & 38.9 \\
\hline 2.0 & 1.34 & 2.0 & 6.22 & 2.0 & 37.2 \\
\hline 3.0 & 1.07 & 3.0 & 5.38 & 3.0 & 35.6 \\
\hline 4.0 & 0.86 & 4.0 & 4.61 & 4.0 & 33.9 \\
\hline 6.0 & 0.54 & 6.0 & 3.29 & 6.0 & 30.7 \\
\hline 9.0 & 0.26 & 9.0 & 1.85 & 9.0 & 25.9 \\
\hline 12.0 & 0.12 & 12.0 & 0.97 & 12.0 & 21.4 \\
\hline 18.0 & - & 18.0 & 0.23 & 18.0 & 13.2 \\
\hline 24.0 & - & 24.0 & - & 24.0 & 6.6 \\
\hline
\end{tabular}

were collected after three different IV bolus doses. The first step should be to plot the data on semi-log graph paper as shown in Figure 1.4. Examination of this plot indicates a curved line, especially at the higher doses. This strongly suggests that a nonlinear elimination process is involved. Thus, a differential equation such as Equation (1.4) may be appropriate.

$$
\frac{d C}{d t}=-\frac{V_{m} \cdot C}{K_{m}+C} \quad C_{0}=\frac{\text { dose }}{V}
$$

The data in Table 1.4 could be modeled using Equation (1.4) to obtain es-

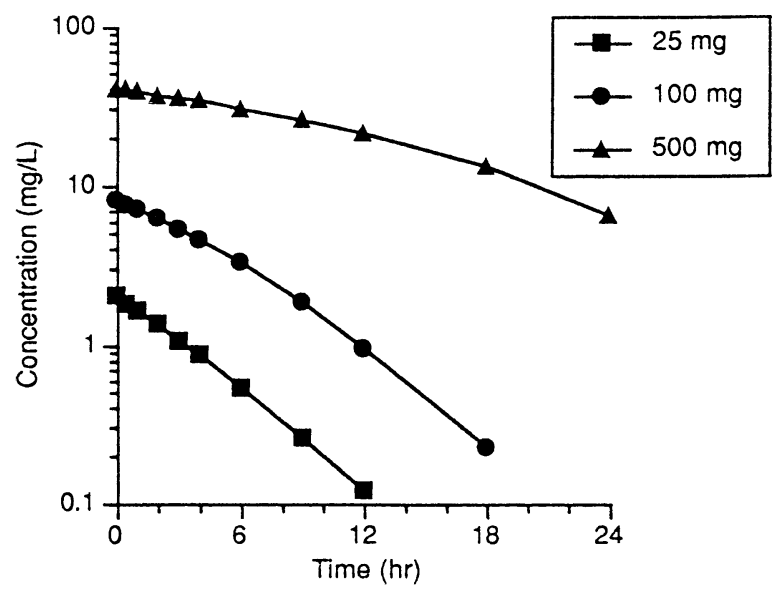

FIGURE 1.4. Plot of drug concentration versus time after various IV bolus doses. 
timates of the three parameters $V_{m}, K_{m}$, and $V$. This analysis will not only condense all the data to a few parameter values, but it will also allow a better understanding of the underlying process.

\subsection{MAKING PREDICTIONS}

Once we have a mathematical model and suitable parameter values, we can start to use the model to make predictions. For example, we can use a mathematical model [Equation (1.5)] to calculate the dose required to achieve a desired plasma concentration versus time profile. What dose is needed to achieve a plasma concentration of $2 \mathrm{mg} / \mathrm{L}$ after $6 \mathrm{hr}$ ? If the elimination rate constant and the apparent volume of distribution have been previously determined as $0.13 \mathrm{hr}^{-1}$ and $15 \mathrm{~L}$, respectively, the required dose can be calculated.

$$
\begin{gathered}
C=\frac{\text { dose }}{V} \cdot e^{-k_{e l} \cdot t} \\
2=\frac{\text { dose }}{15} \cdot e^{-0.13 \cdot 6} \\
\text { dose }=65 \mathrm{mg}
\end{gathered}
$$

A complete concentration versus time profile (out to $6 \mathrm{hr}$ at least) can be calculated with Equation (1.5) using this calculated dose of $65 \mathrm{mg}$. The results of this calculation are shown in Figure 1.5. An extension of this

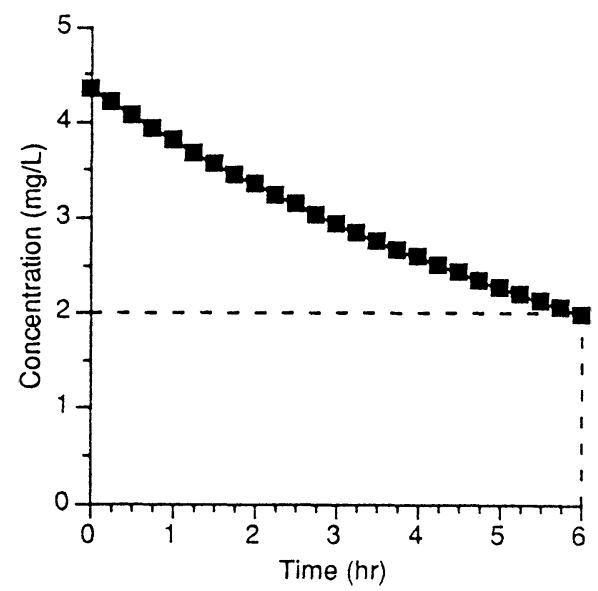

FIGURE 1.5. Plot of drug concentration versus time after a $65 \mathrm{mg} \mathrm{IV} \mathrm{bolus} \mathrm{dose.}$ 


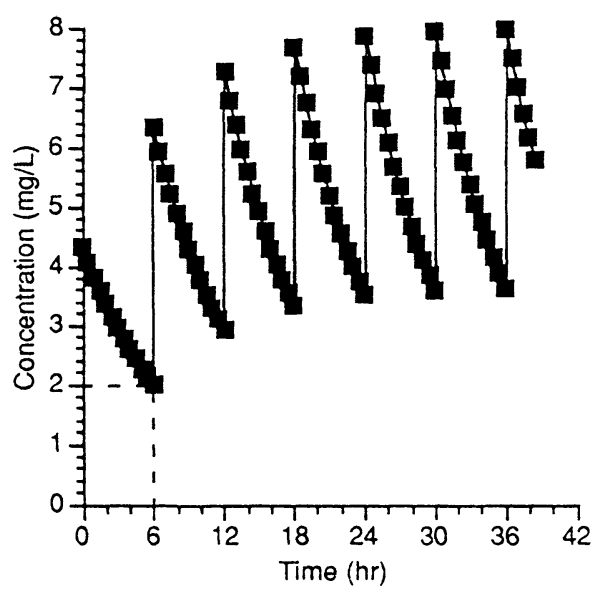

FIGURE 1.6. Plot of drug concentration versus time after a $65 \mathrm{mg} \mathrm{IV}$ bolus dose every six hours.

mathematical model can be used to calculate plasma concentrations after repeated doses. Equation (1.5) provides Equation (1.6) after equal multiple doses at equal dosing intervals.

$$
C=\frac{\text { dose }}{V} \cdot\left[\frac{1-e^{-n \cdot k_{e l} \cdot r}}{1-e^{-k_{e l} \cdot \tau}}\right] \cdot e^{-k_{e l} \cdot t}
$$

where $n$ is the number of doses administered, $\tau$ is the dosing interval, and $t$ is the time since the last dose. With the values of the parameters, $k_{e l}$ and $V$ from a previous modeling study, plasma concentrations after repeated IV doses (equal dose-equal interval), can be calculated using Equation (1.6) as shown in Figure 1.6. Thus, using Equation (1.6) it is possible to calculate peak and trough concentrations after repeated doses, or to calculate doses required to achieve a required peak or trough concentration. 


\section{References}

Akaike, H. 1974. "A New Look at the Statistical Model Identification," IEEE Trans. Automat. Control, 19: 716-723.

Beal, S.L. and L.B. Sheiner . 1989. NONMEM Users Guide-Part I Users Basic Guide, NONMEM Project Group, UCSF, San Francisco, CA.

Benet, L.Z. and J.S. Turi . 1971. "Use of the General Partial Fraction Theorem for Obtaining Inverse Laplace Transforms in Pharmacokinetic Analysis," J. Pharm. Sci., 60: 1593-1594.

Benet, L.Z. 1972. "General Treatment of Linear Mammillary Models with Elimination from any

Compartment as Used in Pharmacokinetics," J. Pharm. Sci., 61: 536-541.

Bischoff, K.B. and R.G. Brown . 1966. "Drug Distribution in Mammals," Chem. Eng. Progr.

Symp. Ser., 66: 33-45.

Bischoff, K.B. 1975. "Some Fundamental Considerations of the Applications of

Pharmacokinetics to Cancer Chemotherapy," Cancer Chemotherap. Reports, Part I, 59:

777-793.

Bischoff, K.B. 1986. "Physiological Pharmacokinetics," Bull Math. Biol., 48: 309-322.

Bourne, D.W.A. , M. Bialer, L.W. Dittert, M. Hayashi, G. Rudawsky , G.D. Koritz and R.F.

Bevill . 1981. "Disposition of Sulfadimethoxine in Cattle: Inclusion of Protein Binding Factors in a Pharmacokinetic Model," J. Pharm. Sci., 70: 1068-1072.

Bourne, D.W.A. 1986. "Multi-Forte, a Microcomputer Program for Modeling and Simulation of Pharmacokinetic Data," Computer Methods and Programs in Biomedicine, 23: 277-281.

Bourne, D.W.A. 1989. "BOOMER, a Simulation and Modeling Program for Pharmacokinetic and Pharmacodynamic Data Analysis," Computer Methods and Programs in Biomedicine, 29: 191-195.

Bourne, D.W.A. and L.W. Dittert . 1990. Pharmacokinetics in Modern Pharmaceutics, Second Ed., G.S. Banker and C.T. Rhodes, eds., New York, NY: Marcel Dekker.

Boxenbaum, H.G. , S. Riegelman and R.M. Elashoff . 1974. "Statistical Estimations in Pharmacokinetics," J. Pharmacokin. Biopharm., 2: 123-148.

Brown, R.F. and K.R. Godfrey . 1978a. "Problems of Determinacy in Compartmental Modeling with Application to Bilirubin Kinetics," Math. Biosci., 40: 205-224.

Brown, R.D. and J.E. Manno . 1978b. "ESTRIP, A BASIC Computer Program for Obtaining Initial Polyexponential Parameter Estimates," J. Pharm. Sci., 67: 1687-1691.

Cutler, D.J. 1978. "Numerical Deconvolution by Least Squares: Use of Prescribed Input

Functions," J. Pharmacokin. Biopharm., 6: 227-241.

D'Argenio, D.Z. and A. Schumitzky . 1992. ADAPT II User's Guide, Biomedical Simulation

Resource, Los Angeles: University of Southern California.

Draper, N.R. and H. Smith . 1966. Applied Regression Analysis, New York, NY: Wiley, pp. 86-100.

Fehlberg, E. 1969. Low-Order Classical Runge-Kutta Formulas With Stepsize Control and Their Application to Some Heat Transfer Problems, NASA Technical Report, NASA TR R-315.

Gallo, J.M. , J.T. Etse , K.J. Doshi , F.D. Boudinot and C.K. Chu . 1991. "Hybrid

Pharmacokinetic Models to Describe Anti-HIV Nucleoside Brain Disposition Following Parent and Prodrug Administration in Mice," Pharm. Res., 8: 247-253.

Gear, C.W. 1971a. "Algorithm 407, DIFSUB for Solution of Ordinary Differential Equations," Comm. ACM, 14: 185-190.

Gear, C.W. 1971b. "The Automatic Integration of Ordinary Differential Equations," Comm. ACM, 14: $176-179$.

Gerald, C.P. and P.O. Wheatly . 1990. Applied Numerical Analysis, Fourth Edition, Reading, MA: Addison-Wesley.

Gibaldi, M. and D. Perrier . 1982. Pharmacokinetics, Second Edition, New York, NY: Marcel Dekker.

Godfrey, K.R. and W.R. Fitch . 1984. "The Deterministic Identifiability of Nonlinear Pharmacokinetic Models," J. Pharmacokin. Biopharm., 12: 177-191.

Hartley, H.O. 1961. "The Modified Gauss-Newton Method for the Fitting of Non-Linear

Regression Functions by Least Squares," Technometrics, 3: 269-280.

Hayden, T.L. , D.W.A. Bourne and Y.T. Fu . 1983. "Fourier-Transform Analysis of

Radiopharmaceutical" Data? Math. Biosci., 63: 71-85. 
Hill, A.V. 1910. "The Possible Effects of the Aggregation of the Molecules of Haemoglobin on its Dissociation Curves," Proc. Physiol. Soc., 40: 4-7.

Jacquez, J.A. and T. Perry . 1990. "Parameter Estimation-Local Identifiability of Parameters," Amer, J. Physiol, 258: E727-E736.

Karol, M. , W.R. Gillespie and P. Veng-Pederson . 1991. AAPS Short Course: Convolution, Deconvolution and Linear Systems, AAPS, Washington, DC, Nov. 17.

Kiwada, H. , K. Morita , M. Hayashi , S. Awazu and M. Hanano . 1977. "A New Numerical Calculation Method for Deconvolution in Linear Compartment Analysis of Pharma-cokinetics," Chem. Pharm. Bulletin., 25: 1312-1318.

Loo, J.C.K. and S. Riegelman . 1968. "New Method for Calculating the Intrinsic Absorption Rate of Drugs," J. Pharm. Sci., 57: 918-927.

Lovering, E.G. , I.J. McGilveray , I. McMillan , and W. Tostowaryk . 1975. "Comparative Bioavailabilities from Truncated Blood Level Curves," J. Pharm. Sci., 64: 1521-1524.

Mandel, J. 1964. The Statistical Analysis of Experimental Data. New York, NY: Interscience, p. 164.

Marino, A.T. , J.J. Distefano and E.M. Landaw . 1992. "DIMSUM: An Expert System for Multiexponential Model Discrimination? Amer. J. Physiol., 262 (EM 25), E546-E556.

Marquardt, D.W. 1963. "An Algorithm for Least Squares Estimation of Nonlinear Parameters," J. Soc. Indust. Appl. Math., 11: 431-441.

Martinez, M.N. and A.J. Jackson . 1991. "Suitability of Various Noninfinity Area Under the Plasma Concentration-Time Curve (AUC) Estimates for Use in Bioequivalence Determinations: Relationship to AUC from Zero to Time Infinity (AUCO- $\infty$ ), Pharm. Res., 8: 512-517.

Mayersohn, M. and M. Gibaldi . 1970. "Mathematical Methods in Pharmacokinetics. I. Use of the Laplace Transform in Solving Differential Rate Equations," Amer. J. Pharm. Ed., 34: 608-614.

Mayersohn, M. and Gibaldi, M. 1971. "Mathematical Methods in Pharmacokinetics. II. Solution of the Two Compartment Open Model," Amer. J. Pharm. Ed., 35: 19-28.

McIntosh, J.E.A. and R.P. McIntosh . 1980. Mathematical Modeling and Computers in Endocrinology, Monographs on Endocrinology. New York, NY: Springer-Verlag, Vol. 16.

Michaelis, L. and M.L. Menten . 1913. "Die Kinetik der Invertinwirkung," Biochem. Z, 49: 333.

Nelder, J.A. and R. Mead . 1965. "A Simplex Method for Function Minimization," Computer J., 7: 308-313.

Peck, C.C. 1984a. "Computer-Assisted Clinical Pharmacokinetics" in Pharmacokinetic Basis for Drug Treatment, L.Z. Benet, N. Massoud and J.G. Gambertoglio, eds., New York, NY: Raven Press, pp. 353-354.

Peck, C.C. , L.B. Sheiner and A.I. Nichols . 1984b. "The Problem of Choosing Weights in Nonlinear Regression Analysis of Pharmacokinetic Data," Drug Metabolism Reviews, 15: 133-148.

Peck, C.C. , S.L. Beal , L.B. Sheiner and A.I. Nichols . 1984c. "Extended Least Squares Nonlinear Regression: A Possible Solution to the 'Choice of Weights' Problem in Analysis of Individual Pharmacokinetic Data," J. Pharmacokin. Biopharm., 12: 545-558.

Provencher, S.W. 1976. "An Eigenfuction Expansion Method for the Analysis of Exponential Decay Curves," J. Chem. Phys., 64: 2772-2777.

Purves, R.D. 1992. "Optimum Numerical Integration Methods for Estimation of Area Under the Curve (AUC) and Area Under the Moment Curve (AUMC), J. Pharmacokin. Biopharm., 20: 211-226.

Saunders, L. and R. Fleming . 1957. Mathematics and Statistics. London, UK: The Pharmaceutical Press.

Schwarz, G. 1978. "Estimating the Dimension of a Model," Ann. Stat., 6: 461-464.

Sedman, A.J. and J.G. Wagner . 1976. "CSTRIP, a FORTRAN IV Computer Program for Obtaining Initial Polyexponential Parameter Estimates," J. Pharm. Sci., 65: 1006-1010.

Selby, S.M. 1974. Standard Math Tables, Twenty-Second Edition, Cleveland, OH: CRC Press. Shargel, L. and A.B.C. Yu . 1993. Applied Biopharmaceutics and Pharmacokinetics, Third Edition, Norwalk, CT: Appleton and Lange.

Sheiner, L.B. , B. Rosenberg and K.L. Melmon . 1972. "Modeling of Individual Pharmacokinetics for Computer-Aided Drug Dosage," Computers and Biomedical Research, 5: 441-459.

Sheiner, L.B. , D.R. Stanski , S. Vozeh , R.D. Miller and J. Ham . 1979. "Simultaneous Modeling of Pharmacokinetics and Pharmacodynamics: Application to d-tubocurarine," Clin. Pharmacol.

Therap., 25: 358-371. 
Urso, R. and L. Aarons . 1983. "Bioavailability of Drugs with Long Elimination Half-Lives," Eur. J. Clin. Pharmacol., 25: 689-693.

Vaughan, D.P. and M. Dennis . 1978. "Mathematical Basis of Point-Area Deconvolution Method for Determining in vivo Input Function," J. Pharm. Sci., 67: 663-665.

Wagner, J.G. and E. Nelson . 1964. "Kinetic Analysis of Blood Levels and Urinary Excretion in the Absorptive Phase After Single Doses of Drug," J Pharm. Sci., 53: 1392-1403.

Wagner, J.G. 1975. Fundamentals of Clinical Pharmacokinetics, Hamilton, IL: Drug Intelligence Publications.

Wagner, J.G. 1993. Pharmacokinetics for the Pharmaceutical Scientist, Lancaster, PA:

Technomic.

Wang, Y.M.C. and R.H. Reuning . 1992. "An Experimental Design Strategy for Quantitating Complex Pharmacokinetic Models - Enterohepatic Circulation with Time-Varying Gallbladder Emptying as an Example," Pharm. Res., 9: 169-177.

Watt, H.A. and L.F. Shampine . 1977. "Subroutine RKF45" in Computer Methods for Mathematical Computations, G.E. Forsythe, M.A. Malcolm and C.B. Moler, eds., Englewood, NJ: Prentice-Hall, pp. 133-147.

Whipple, J.K. , K.S. Lewis , S.D. Weitman , R.K. Ausman , D.W.A. Bourne , W. Andrews , M.B. Adams , E.A. Sasse and E.J. Quebbeman . 1994. "Pharmacokinetic Evaluation of a New Oral Cyclosporine Formulation," Pharmacotherapy, 14: 105-110.

Yamaoka, K. , T. Nakagawa and T. Uno . 1978. "Application of Akaike's Information Criterion (AIC) in the Evaluation of Linear Pharmacokinetic Equations," J. Pharmacokin. Biopharm., 6: 165-175.

Yamaoka, K. , Y. Tanigawara, T. Nakagawa and T. Uno . 1981. "A Pharmacokinetic Analysis Program (Multi) for Microcomputer," J. Pharmacobio-dyn., 4: 879-885.

Yamaoka, K. and T. Nakagawa . 1983. "A Nonlinear Least Squares Program Based on Differential Equations, Multi (Runge) for Microcomputers," J. Pharmacobio-dyn., 6: 595-606. Yamaoka, K. , T. Nakagawa, H. Tanaka, M. Yasuhara, K. Okumura and R. Hori . 1985. "A Nonlinear Multiple Regression Program Multi2 (Bayes) Based on Bayesian Algorithm for Microcomputers," J. Pharmacobio-dyn., 8: 246-256.

Yano, Y. , K. Yamaoka and H. Tanaka . 1989. "A Nonlinear Least Squares Program, Multi (Filt), Based on Fast Inverse Laplace Transform for Microcomputers," Chem. Pharm. Bulletin, 37: 1035-1038.

Yeh, K.C. and K.C. Kwan . 1978. "A Comparison of Numerical Integrating Algorithm by Trapezoidal Lagrange and Spline Approximation," J. Pharmacokin. Biopharm., 6: 79-98. 